\title{
Breeding for Resistance to Fusarium Wilt of Tomato: A Review
}

\author{
Jessica Chitwood-Brown ${ }^{1}$, Gary E. Vallad ${ }^{2} \mathbb{D}$, Tong Geon Lee ${ }^{1,3,4} \mathbb{D}$ and Samuel F. Hutton ${ }^{1,3, *}$ \\ 1 Horticultural Sciences Department, University of Florida, Gainesville, FL 32611, USA; \\ jchitwood@ufl.edu (J.C.-B.); tonggeonlee@ufl.edu (T.G.L.) \\ 2 Plant Pathology Department, University of Florida, Gainesville, FL 32611, USA; gvallad@ufl.edu \\ 3 Gulf Coast Research and Education Center, University of Florida, Wimauma, FL 33598, USA \\ 4 Plant Molecular and Cellular Biology Graduate Program, University of Florida, Gainesville, FL 32611, USA \\ * Correspondence: sfhutton@ufl.edu
}

Citation: Chitwood-Brown, J.;

Vallad, G.E.; Lee, T.G.; Hutton, S.F. Breeding for Resistance to Fusarium Wilt of Tomato: A Review. Genes 2021, 12, 1673. https://doi.org/10.3390/ genes12111673

Academic Editors: Mathilde Causse and Antonio Granell

Received: 30 September 2021

Accepted: 21 October 2021

Published: 23 October 2021

Publisher's Note: MDPI stays neutral with regard to jurisdictional claims in published maps and institutional affiliations.

Copyright: (c) 2021 by the authors. Licensee MDPI, Basel, Switzerland. This article is an open access article distributed under the terms and conditions of the Creative Commons Attribution (CC BY) license (https:// creativecommons.org/licenses/by/ $4.0 /)$.

\begin{abstract}
For over a century, breeders have worked to develop tomato (Solanum lycopersicum) cultivars with resistance to Fusarium wilt $(F o l)$ caused by the soilborne fungus Fusarium oxysporum f. sp. lycopersici. Host resistance is the most effective strategy for the management of this disease. For each of the three Fol races, resistance has been introgressed from wild tomato species, predominately in the form of R genes. The I, I-2, I-3, and I-7 R genes have each been identified, as well as the corresponding Avr effectors in the fungus with the exception of Avr7. The mechanisms by which the R gene protein products recognize these effectors, however, has not been elucidated. Extensive genetic mapping, gene cloning, and genome sequencing efforts support the development of tightly-linked molecular markers, which greatly expedite tomato breeding and the development of elite, Fol resistant cultivars. These resources also provide important tools for pyramiding resistance genes and should support the durability of host resistance.
\end{abstract}

Keywords: tomato; tomato wild relatives; breeding; genetics; linkage drag; gene pyramiding; durable resistance

\section{Introduction}

Tomato (S. lycopersicum) is one of the most important vegetable crops in the world, with over 180 million tons produced worldwide in 2019 and just over 5 million ha harvested (Faostat, http:/ / www.fao.org/faostat/en/\#data/QC/visualize, accessed on 14 September 2021). Between 1999 and 2019, the global area harvested increased by $27 \%$ while production increased by 66\% (Faostat, http:/ / www.fao.org/faostat/en/\#data/QC/visualize, accessed on 14 September 2021). This gain in productivity is the result of research in many areas, notably the improvement of tomato varieties through breeding efforts.

Tomato breeding has focused on improving traits important to growers and consumers, including fruit quality characteristics, yield, and disease resistance. Because tomato is susceptible to more than 200 pests and pathogens [1,2], breeding for appropriate disease resistances is crucial to the success of a tomato cultivar. However, unless a production area is under high disease pressure, resistance alone is not likely to make a cultivar successful. Tomato growers must produce fruit that satisfy market demands and meet industry standards in order to make a profit, and under ordinary circumstances, a new cultivar with disease resistance must perform at least comparably to existing susceptible cultivars with respect to fruit quality traits, yield, and other critical characteristics.

Cultivated tomato is considered to have low genetic diversity due to bottlenecks in domestication and the subsequent effects of artificial selection, but wild tomato species harbor a great deal of variation $[3,4]$. For over a century, tomato breeders have utilized the genetic diversity within wild tomato species to introduce desirable traits, especially disease resistance genes, by crossing these with cultivated tomato [4]. In this review, we illustrate the efforts of tomato breeding for resistance to Fusarium wilt, including how disease resistance was identified in wild tomato species, the cloning of resistance genes, 
and the transition from phenotypic selection to marker assisted breeding with currently available tools.

\section{Fusarium Wilt Description}

F. oxysporum (Schlecht. emend. Snyder \& Hansen), is a cosmopolitan soil fungus that exists as a saprophyte due to its ability to degrade lignin and other complex carbohydrates and is a common epiphyte and endophyte of plant roots [5,6]. However, within F. oxysporum exists more than 120 different specialized forms capable of causing severe disease losses on diverse vegetable, field, and plantation crops, although each form is limited to a range of hosts and designated as formae specialis (f. sp.) [7]. Fusarium wilt of tomato, caused by F. oxysporum f. sp. lycopersici ( $F o l)$, threatens US and global tomato production for both processing and fresh-market systems. Fol was first described in England in 1895 and has since been found in more than 40 countries [8]. The fungus penetrates plant roots before colonizing the vascular tissue. Initial disease symptoms begin as pronounced chlorosis and wilting of lower basal leaves that progresses acropetally to the upper leaves (Figure 1). These symptoms are often asymmetrical, restricted to one or two branches of the plant or even to one side of a leaf. As symptoms progress, wilting can occur either on the entire plant or one side, and early wilting may be more noticeable in the afternoon, with the plant appearing to recover overnight [8]. Browning in the vascular tissue of the stems as the pathogen colonizes the vascular tissue is commonly observed (Figure 1). Eventually, the disease leads to a rapid decline of the plant, accelerated fruit ripening, and plant death. Disease development is favored by sandy, acidic soils and warm temperatures $\left(25-28^{\circ} \mathrm{C}\right)[9,10]$.

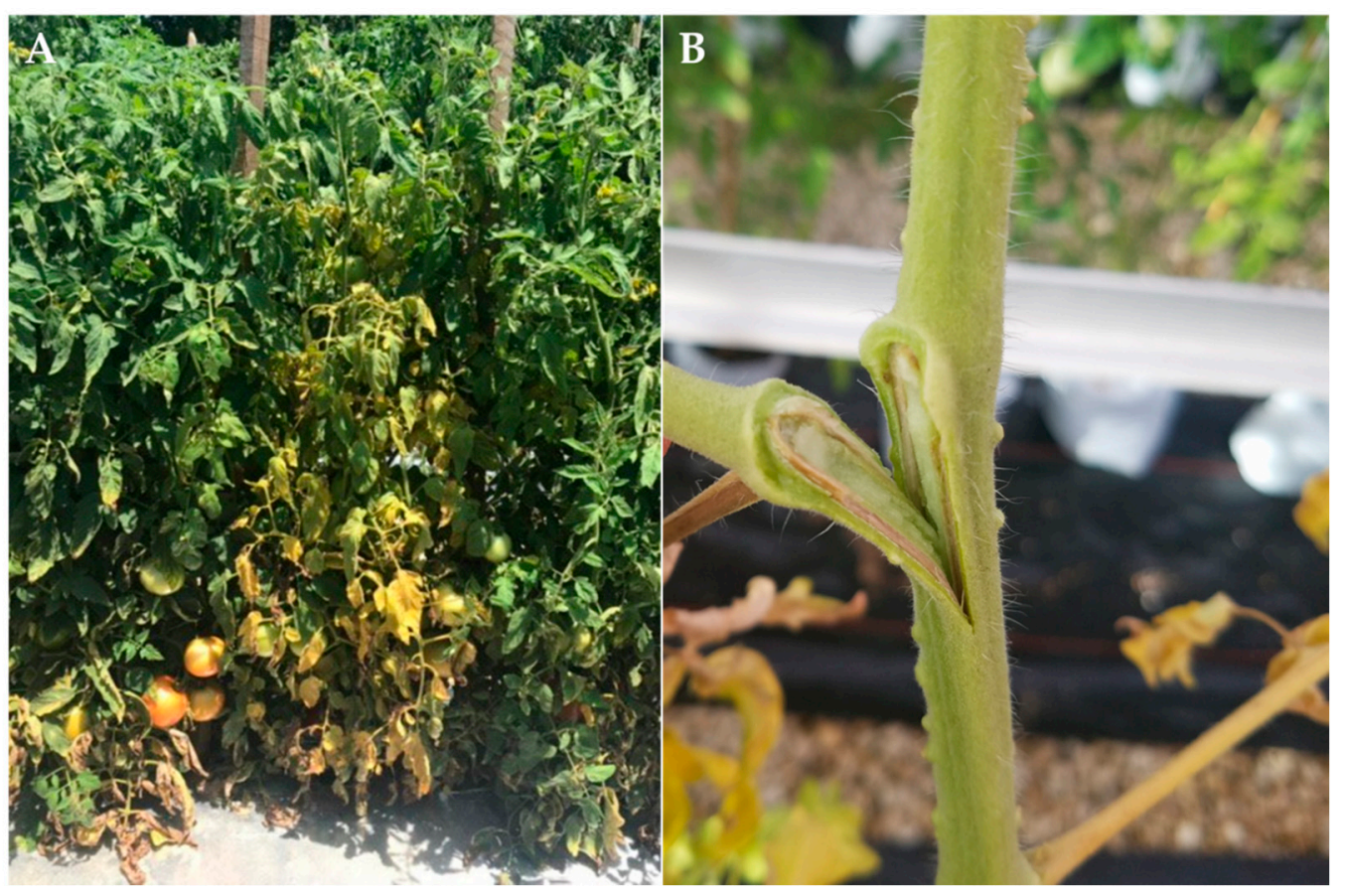

Figure 1. (A) Disease symptoms in a susceptible tomato (S. lycopersicum) plant grown to near maturity in field conditions. (B) Vascular browning in the stem of a susceptible tomato plant.

Fol produces several asexual structures, including micro- and macroconidia and thickwalled chlamydospores that can survive in the soil for up to ten years [8]. Inoculum may be introduced into uninfested soil via the aerial dissemination of conida from the surfaces of infected plants under certain conditions [11]. The pathogen may also be spread on infected transplants or through the movement of contaminated soil on equipment, workers, or packing boxes [8]. Once introduced into a field, Fol is almost impossible to eliminate, as it can survive nearly indefinitely in soil as either chlamydospores in plant residues or as a 
common root epiphyte/saprophyte on numerous weeds without causing disease [12]. In the absence of control strategies, such as fumigation and host resistance (which is the focus of this review), Fol can result in up to complete crop loss [13].

\section{Fol Control Strategies}

Efforts to control Fol have included cultural, biological, chemical, and host resistance strategies to varying degrees of success. Altering the soil $\mathrm{pH}$ using lime and nitrogen amendments resulted in a reduction of disease incidence for all three races of Fol but did not eliminate crop losses [10]. Long fallow (where fields are not cultivated for a certain duration of time) or crop rotations are recommended to help reduce soil levels of Fol [8]. Jones et al. [14] observed reduced disease incidence and increased yields when a field was left uncultivated for a 9-month period. Corato et al. [15] reported a reduction in the total amount of spores and pathogenicity of Fol when tomato crops were rotated with durum wheat compared to tomato monoculture. While these strategies may reduce disease incidence, the benefits of crop rotation or the duration necessary to reduce Fol or similar soilborne pathogens to an acceptable level in tropical and subtropical production systems has not been adequately addressed. Further, similarly to many specialty crops in the U.S., the economics of tomato production do not allow for abandoning problematic fields or developing additional fields, and land rotations are limited due to the intense nature of tomato production. Thus, these strategies are not widely used in commercial tomato production. Studies have also investigated the utility of biological control [16-18]. However, these studies take place almost entirely in controlled greenhouse or growth chamber settings and further study into field efficacy of these control measures is needed. Nonetheless, like the previous control methods described, biological control measures do not eliminate the disease entirely and, to date, there are no reports of this strategy being implemented successfully on a commercial scale.

In many places throughout the world, commercial tomato production requires soil fumigation to limit the impact of soilborne pathogens on production. From the 1970's until 2014, the US tomato industry relied heavily on the preplant fumigant methyl bromide to maintain economical production levels [19-21]. Methyl bromide, a fumigant that quickly volatilizes once applied to soil, provided control against many soilborne pathogens in addition to nematodes and weeds over a broad range of environmental conditions, and had greater efficacy for controlling Fol than most cultural practices. However, designation as an ozone depleting chemical in 1993 under the Montreal Protocol led to the global phasing out of methyl bromide usage. Access to limited quantities of methyl bromide for tomato production through successive critical use exemptions ended 31 December 2014.

Several registered alternative fumigants to methyl bromide exist (such as chloropicrin, dimethyl disulfide, 1,3-dichloropropene, and numerous isothiocyanate generators), although all lack the broad-spectrum activity and the volatility that made methyl bromide so highly effective [20]. Placement of the fumigant within the soil was demonstrated to affect soil levels of Fol, such that supplemental application of the chemicals alongside the raised soil bed reduced disease incidence $[22,23]$. However, this did not consistently result in an increase in yield [22]. The transition away from methyl bromide has been associated with losses of nearly $\$ 4000$ per acre in Florida, one of the largest production areas for fresh-market tomatoes in the USA [21].

Host resistance is the most effective control strategy for Fol.

\section{Breeding for Resistance}

Efforts to develop tomato cultivars with resistance to Fol began in the 1900s at agricultural research stations across the USA, and some of the first tests were conducted in Florida in 1905 [24]. Resistance to the three races of Fol was discovered in wild tomato accessions, many of which have been used to study resistance and some to introduce resistance into cultivars for tomato production regions around the world [24-26]. Most 
of the genes identified for Fol resistance, and all the genes used commercially, are single, dominant resistance genes, or $\mathrm{R}$ genes.

Resistance to Fol was first identified by Bohn and Tucker [24] after extensive screening of wild tomato relatives in search of resistance which could be crossed with cultivated tomato. The researchers identified one resistant accession of S. pimpinellifolium, Missouri accession 160 (PI79532), which contained a single, dominant resistance locus they termed $I$ for "Immunity". This source was easily crossed into S. lycopersicum, and 'Pan America', containing the I gene, was later released as the first cultivar with Fol resistance [27]. The I gene was mapped to chromosome 11 [28].

A second race of Fol (Fol2) was subsequently reported by Alexander and Tucker [29], and resistance was again discovered in wild tomato germplasm [25]. However, efforts to breed for resistance were not commenced until the 1960s, when Florida's tomato industry suffered tremendous crop losses due to outbreaks of Fol2 [30]. PI126915, a naturally occurring hybrid between S. pimpinellifolium and S. lycopersicum [25], possessed simply-inherited, dominant Fol2 resistance in addition to resistance to Fol1 and other fungal pathogens including gray leaf spot (Stemphylium spp.) and Cladosporium (Passalora fulva) [30,31]. Cirulli and Alexander [32] determined the Fol1 and Fol2 resistances in this accession were conferred by two independent genes, and they designated the gene for Fol2 resistance as I-2, which was also genetically mapped to chromosome 11 [33-35]. 'Walter' was released in 1969 as the first commercial variety with resistance to both Fol1 and Fol2 [36].

The third Fol race (Fol3) was initially reported in Australia in 1979 and then in Florida in 1982 [37,38]. Resistance to race 3 in the S. pennellii accession PI414773 was first described by McGrath et al. [39], and Scott and Jones [40] soon after identified a dominant Fol3 resistance locus from the S. pennellii accession LA716. Both of these resistances were designated I-3, and the LA716-derived resistance developed by Scott and Jones [40] has served as the primary source of Fol3 resistance for cultivar development around the world. Bournival et al. [41] mapped I-3 to chromosome 7, linked with the isozyme marker Got-2. Interestingly, the resistance introgressed from PI414773 was later determined to be based not on I-3, but on a separate locus on chromosome 8 that was designated I-7 [42,43].

Resistance beyond that to Fol3 has also been observed in PI414773 and LA716, although the loci responsible for this resistance have been contested. McGrath et al. [39] reported that two genes in PI414773 were responsible for resistance to Fol2, and one of these was determined to be allelic with the I-2 gene. The location of the second gene, although not demonstrated at the time, likely corresponds to $I-7$, which was recently demonstrated to confer resistance to Fol2 as well as to Fol3. LA716 is also resistant to races 1 and 2 [40], and several studies have implicated the involvement of $I-3$ or of nearby genes in each of these responses. Based on phenotypes of recombinants developed by Bournival et al. [44], the possibility of a separate gene linked to I-3 and conferring resistance to Fol1 was supported, but cosegregation of Fol2 with Fol3 resistance led to the conclusion that Fol2 resistance was conferred by I-3 itself or a by a tightly linked gene. Sarfatti et al. [45] likewise investigated the relationship between race 1 resistance and the $I-3$ locus, and these authors described a separate I1 locus that mapped to a $37 \mathrm{cM}$ region on chromosome 7 but is distinct from $\mathrm{I}-3$. Based on disease responses of a panel of recombinant lines having various combinations of the I, I-2, and I-3 genes, Scott et al. [33] also demonstrated an intermediate Fol2 effect by I-3 or by a tightly linked gene, and they further supported the alleged I1 locus. Despite the commonalities among these studies, all were conducted during a time of limited marker coverage and prior to knowledge of the precise locations of each of the introgressed resistance genes. More recently, Do et al. [46] challenged the existence of I1, instead concluding that the $I-3$ gene itself confers a level of resistance to races 1 and 2 . Using recombinant lines and Fol1 and Fol2 isolates with knockouts of the Avr3 effector (which is necessary for I-3-mediated resistance), they observed that lines which lacked the I-3 locus were susceptible to race 2 and that a functional Avr3 was necessary for intermediate resistance to races 1 and 2. Although the existence of $I 1$ or an unknown Fol2 resistance gene linked to $I-3$ is therefore unlikely, it may still be useful to challenge lines containing 
I-3 alone or containing a knock-out of I-3 with Fol1 and Fol2 to better understand the effect of $I-3$ against races 1 and 2 .

Three loci conferring partial resistance to Fol 2 were also identified by Sela-Buurlage et al. [47]. Using 53 introgression lines carrying various chromosomal segments from $S$. pennellii accession LA716 within a S. lycopersicum background [48], the authors identified the S. pennellii I-5 and the I-6 loci on chromosomes 2 and 10, respectively. In addition, the greater susceptibility of one line carrying a S. pennelli introgression on chromosome 2 between markers CT75 and TG91 prompted the conclusion that a S. lycopersicum resistance allele is present at this locus, which the authors named $I-4$. But besides being named, the effects of these loci have neither been validated in separate populations nor have they been deployed commercially.

\section{Gene Cloning}

The division of Fol into three races on the basis of overcoming resistance genes implies a gene-for-gene model for the host-pathogen system between the tomato I genes and Fol effectors. By this model, each I gene encodes a protein product that confers resistance dependent on a specific effector produced by Fol. Several effectors have been identified as a series of proteins detected within tomato xylem following Fol infection and are encoded by Secreted in xylem (SIX) genes, some of which are also designated as avirulence or Avr genes.

Prior to the release of a published tomato genome [49], only I-2 had been cloned and characterized [34]. In recent years, however, I, I-3, and I-7 have been identified (Table 1), providing knowledge of each of the commercialized I genes [34,42,50,51]. The corresponding effectors required for resistance conferred by $I, I-2$, and $I-3$ have also been identified as Avr1 (SIX4), Avr2 (SIX3), and Avr3 (SIX1), respectively (Table 1) [52-54].

Table 1. Resistance genes introgressed from wild tomato species and their corresponding effectors of Fusarium oxysporum f. sp. lycopersici.

\begin{tabular}{ccccc}
\hline R Gene & Gene Class & Locus ID & Source & $\begin{array}{c}\text { Effector } \\
\text { Recognized }\end{array}$ \\
\hline$I$ & LRR-RLP & Solyc11g011180 & S. pimpinellifolium & Avr1 (Six4) \\
$I-2$ & CC-NB-LRR-RLP & Solyc11g071430 & S. pimpinellifolium & Avr2 (Six3) \\
$I-3$ & SRLK & Solyc07g055640 & S. pennellii & Avr3 (Six1) \\
$I-7$ & LRR-RLP & Solyc08g077740 & S. pennellii & unknown \\
\hline
\end{tabular}

Catanzariti et al. [51] identified Solyc11g011180 on chromosome 11 as the I gene, which encodes an atypical membrane-anchored leucine-rich repeat (LRR) receptor-like protein (RLP). I has several features which contrast with other known plant defense genes encoding LRR-RLPs. Some of these features are as follows: it does not belong to a gene cluster, introns are contained in the coding sequence, and specificity for Avr1 is defined by the C-terminus of the protein [51].

$I-2$ was the first of the $I$ genes to be isolated, and resistance is dependent on the effectors Avr2 (SIX3) and SIX5 ([34,54,55]. The I-2 gene, Solyc11g071430, is also on chromosome 11 and encodes a coiled-coil (CC) nucleotide-binding (NB) LRR protein [34]. I-2 is part of the I2C gene family, a complex of genes with structural similarities to NB-LRR resistance genes [34,56]. Although Ori et al. [56] reported that one gene in the cluster besides I-2 (viz. I2C-1) conferred partial Fol2 resistance in transgenic plants, Simons et al. [34] contradicted this, instead demonstrating that resistance is only given by I-2. The latter group suggested the reason for this discrepancy lay in the use by Ori et al. [56] of a tomato background with the I gene. In contrast, Simons et al. [34] had used material with no other Fol resistance, and they further stated that disease symptoms are less severe in plants infected with race 2 when race 1 resistance is present, although there are no published data to support this claim. Houterman et al. [54] found that SIX3 was necessary for I-2 resistance and thus called it Avr2. However, Ma et al. [55] later found that an additional SIX gene, SIX5, was 
also required for $I-2$ resistance, as a knock-out of either SIX3 or SIX5 eliminated resistance and both were required for full pathogenicity. SIX3 and SIX5 also share a promoter region that controls their co-expression, with SIX5 interacting with Avr2 to facilitate cell-tocell movement of Avr2 within the host via plasmodesmata [57,58]. Three separate point mutations within the SIX3 (Avr2) gene have been described to prevent recognition by I-2 but do not affect pathogenicity, resulting in the emergence of race 3 [54].

The I-3 gene was identified as SpSRLK-5 or Solyc07g055640 and encodes an S-receptorlike-kinase (SRLK) on chromosome 7 [50]. I-3-mediated resistance is dependent on Avr3 (SIX1), the first avirulence factor of F. oxysporum identified [52]. Transgenic plants containing SpSRLK-5 challenged with an Fol3 knock-out mutant that lacked Avr3 (Fol3 $\triangle$ Avr3) were susceptible, confirming that SpSRLK-5 is the $I-3$ gene. Unlike most plant disease resistance genes, $I-3$ as a member of an SRLK gene family does not include a LRR domain; $I-3$ is only the second resistance gene known to encode an SRLK, the first being the Pi- $d 2$ gene from rice [50]. SpSRLK-5 is located among several SRLK genes in the I-3 region that vary in their protein sequence similarity with one another, but the function of these SRLK paralogs has not been investigated. Interestingly, SpSRLK-6 shares 91\% sequence identity with SpSRLK-5, and disease development in transgenic lines with the SpSRLK-6 paralog was less severe than in susceptible controls [50]. Thus, it is possible that this gene is also involved in a separate disease resistance response.

Although first discovered by McGrath et al. [39], I-7 was not identified as a separate locus from I-3 until the 2006 report of Lim et al. [43]. The I-7 gene (Solyc08g077740) encodes an LRR-receptor-like-protein and is borne on a small (approximately $210 \mathrm{~kb}$ ) introgression on chromosome 8, which was identified using an RNA-seq analysis of root transcripts after previous genome wide marker screens failed to locate the introgression [42,59]. The Avr effector protein(s) corresponding to I-7-mediated resistance have not yet been identified. I-7 also confers resistance to Fol1 and Fol2 based on seedling disease assays in which I-7 was overexpressed in the Fol susceptible 'Moneymaker' background via transformation, though the effect of $I-7$ against Fol 1 and Fol 2 under native expression has not been demonstrated.

$I-4, I-5$, and $I-6$ have not been cloned, and the mechanisms of these resistances have not been explored.

\section{Linkage-Drag Associated with I-3 Resolved}

Although cultivars containing $I-3$ have been commercially available since the mid 1990's, breeders have experienced considerable difficulty developing commercially acceptable Fol3 resistant hybrids. Some of the earliest I-3 parents had greater susceptibility to blossom-end rot [60], and smaller fruit size was also demonstrated in plants that were homozygous for I-3 compared to plants heterozygous for the gene [61]. Recently, ChitwoodBrown et al. [62] found that the I-3 introgression decreases fruit size by approximately $21 \%$. Furthermore, Hutton et al. [63] demonstrated that the $I-3$ introgression in advanced breeding material contributed as much as a $20 \%$ increase in the severity of bacterial spot symptoms caused by Xanthomonas perforans race T4 in $I-3 / I-3$ plants relative to $i-3 / i-3$ plants.

Li et al. [64] developed recombinant inbred lines (RILs) which segregated for different portions of the $S$. pennellii introgression by screening for cross-over events near the $I-3$ gene. Using field disease screens, they demonstrated that increased sensitivity to bacterial spot co-segregated with the proximal portion of the $S$. pennellii introgression, above the $I-3$ gene, regardless of whether the $I-3$ gene itself was present or absent. These findings collectively suggested that increased sensitivity to bacterial spot is not due to the $I-3$ gene itself but results from linkage with negative alleles. Building on this work, ChitwoodBrown et al. [62] reduced the $I-3$ introgression to approximately $140 \mathrm{~Kb}$, encompassing only 13 annotated genes besides $I-3$ and excluding the proximal region previously implicated. Field evaluations of segregating backcross populations demonstrated that the reduced $I-3$ introgression is free of linkage with both bacterial spot sensitivity and reduced fruit size. Germplasm containing the reduced $I-3$ introgression is available, providing breeders with improved Fol3 resistance resources for use in cultivar development [62]. 


\section{Gene Expression and Host-Pathogen Interactions}

Although the exact mechanisms by which the I genes confer resistance are not well understood, many studies have explored gene expression to attempt to elucidate the host-pathogen interactions. Early investigations utilized grafting between 'Pan America' (containing I) and 'Bonny Best' (Fol susceptible) and found that 'Pan America' rootstocks were sufficient for providing resistance to 'Bonny Best' scions while the reciprocal combination resulted in susceptibility. Thus, they concluded that resistance was localized to the roots [65]. However, Snyder et al. [66] demonstrated in 'Pan America' that although the fungus traveled beyond the roots and upward into the xylem of the stem, the plants did not always show foliar symptoms. They found no evidence of an inhibitory substance produced by the plant in the xylem and further reported that resistance functions in living cells throughout the plant, not only in the roots.

Nonetheless, the first point of contact between the pathogen and the host plant occurs in the roots, and many studies have examined expression of resistance genes in the roots, in addition to searching for interactions between the gene transcripts and fungal effectors in this tissue. Gonzales-Cendales et al. [42] in fact identified the I-7 gene using RNA-seq to detect transcripts in root tissue that corresponded with resistance. In contrast, $I-3$ is expressed at greater levels in leaf tissue than in the roots, where it is barely detectable [50]. Mes et al. [67] studied expression of the $I-2$ gene using GUS reporting ( $\beta$-glucuronidase reporter gene fused to $I-2$ promotor) and detected expression in roots, stems, and leaves with the highest levels of expression in xylem parenchyma cells. Interestingly, I-2 is expressed regardless of infection by Fol2 [67]. They also demonstrated that containment of fungal colonization in resistant plants takes place in xylem parenchyma cells, indicating a possible site for Avr $2 / I-2$ interaction, although direct interaction between the two proteins was not observed. Houterman et al. [54] also studied the relationship between I-2 and Avr2 and demonstrated using agroinfiltration in Nicotiana benthamiana that Avr2 can be recognized intracellularly. However, direct interaction between the proteins has yet to be observed.

Other attempts to study protein-protein interactions have likewise proved unsuccessful. Coexpression of $I$ and Avr1 in tobacco induced necrosis, which was helpful for confirming the identity of the I gene, but a direct interaction was not found [51]. Catanzariti et al. [50] utilized yeast two hybrid assays to investigate $I-3$ and Avr3 using various domains of $I-3$, but they were also unable to detect any interaction. Furthermore, coexpression of these two genes in tobacco did not result in any detectable phenotype.

All tested Fol isolates carry SIX1 (Avr3) and SIX2 [52,68]. However, Rep et al. [52] observed that a collection of race 1 isolates were virulent on a tomato line containing $I-3$, even though they contained an intact Avr3, and the authors suggested these isolates overcame I-3-mediated resistance by some other fungal factor. Upon identification of Avr 1 (SIX4), Houterman et al. [53] reported that in addition to acting as an avirulence factor in the presence of the $I$ gene, this effector suppressed resistance conferred by the $I-2$ and $I-3$ genes. Therefore, based on the current model of the Fol-tomato pathosystem, neither I-2 nor I-3 should provide effective resistance to race 1 strains, even though Fol1 contains Avr 2 and Avr3. Consistent with this, Do et al. [46] reported that $I-3$ conferred only partial resistance to Fol1 due to suppression by Avr1, although the level of resistance was not clearly defined. Tomato breeders have therefore been advised to continue selecting for at least the $I$ and $I-3$ genes for cultivar development. Interestingly, Gonzalez-Cendales et al. [42] reported that the I-7 gene confers resistance to Fol1 and Fol2 and is not suppressed by Avr1, a possible indication that this gene functions in a resistance pathway independent of the $I-3$ gene.

Although the function of SIX genes as effectors has been described, their presence alone is not necessarily indicative of pathogenicity. Jelinski et al. [69] identified F. oxysporum isolates that were recovered from the soils of tomato fields with a history of Fusarium wilt, which possessed the full repertoire of SIX genes but were nonpathogenic on tomato. It is possible that other chaperone genes, similar to SIX5, may be required for pathogenicity and host resistance [55]. Furthermore, those SIX genes required for pathogenicity in Fol 
lie within an accessory chromosome (also referred to as a supernumerary, B, or lineagespecific chromosome) that can be horizontally transferred between isolates, conferring pathogenicity to otherwise nonpathogenic isolates [70,71]. Combined with the lack of any observation of direct interaction between protein products of the I genes and Avr genes, addressing this gap in the understanding of the Fol-tomato system would be helpful for breeders to make more informed decisions as to which I genes are best to deploy and how they should be pyramided.

\section{Phenotypic Selection Methodologies}

Phenotypic screening has always been an important aspect in the advancement of disease resistance. Although such screens were formerly an indispensable component of all selection efforts, modern breeding programs often utilize molecular markers to guide their selections. Even so, phenotypic screening and selection remains necessary for identifying resistance sources, for gene discovery efforts, and for validating resistance in advanced materials.

The earliest tests to identify Fol resistance were conducted in fields that were naturally infested with the pathogen [24]. Soil could also be artificially infested by adding cultures of the fungus grown in oats or cornmeal. Field testing, however, was cumbersome and was limited by the amount of time, land, and resources required to test at most a few thousand plants per season [72]. Field testing was also hampered by the presence of diseases other than Fusarium wilt and by differences in environmental conditions among regions [72]. Variation in the naturally occurring inoculum load of the soil further confounded results, often producing "escapes"-or genetically susceptible plants that remain healthy in the screen. Artificial inoculation of soil, both in the field and the greenhouse, was used to reduce the number of escapes and improve breeding efforts [24]. After experimenting with numerous inoculation methods, Wellman [72] introduced a technique in which the fungus was directly applied to seedling roots by immersing roots in a suspension of hyphae and spores. Seedlings were grown in a greenhouse until approximately four true leaves had developed, and then roots were washed free of soil and dipped in the inoculum. The seedlings were then transplanted into steam-sterilized soil and maintained in a greenhouse at 25 to $30^{\circ} \mathrm{C}$, an optimal temperature range for disease development. This technique, which became known as the Wellman root-dip method, was well-suited for quickly screening large numbers of plants and obtaining consistent, repeatable results. Although some field testing continued, the Wellman root-dip method served as the basis of Fusarium wilt disease assays from that point forward, and this technique, or modifications to it, are most frequently described in the literature. Common modifications include adjustments to the inoculum concentrations (which typically range between $1 \times 10^{6}$, and $1 \times 10^{7}$ conidia $/ \mathrm{mL}$ ) or to seedling age at the time of the inoculation (which commonly ranges between cotyledon and fourth true leaf state) $[33,42,52,62]$. Seedlings are typically evaluated after two to three weeks and are considered diseased if the plants are dead or exhibit clear stunting, wilting, chlorosis, enlarged stems, or stem collapse [33,42,62]. Plant roots may be dissected to determine if vascular browning is present, which is also indicative of $\mathrm{Fol}$ infection [33,62]. Figure 2 depicts symptoms commonly observed in seedling disease assays.

Although the Wellman root-dip method has several advantages over field testing, it is not without weakness. Wellman [72] noted that some seedlings appeared infected when the evaluation was done one week after inoculation, and that these plants seemed to outgrow the symptoms if given more time, later appearing normal in development. Thus, the timing of evaluation may contribute to the possibility that the disease response of a plant is falsely recorded during a seedling assay. Inoculum concentration and the age of the plant at the time of infection has also been reported to influence resistance response [73,74]. Some lines can appear to be susceptible in root-dip disease assays but have much less disease incidence when subjected to field tests [74]. As an example, Chitwood-Brown et al. [62] observed that resistance conferred by $I-7$ was significantly impacted by inoculum 
concentration, where the proportion of healthy plants decreased from $86 \%$ to $23 \%$ as the inoculum concentration increased from $10^{5}$ to $10^{7}$ spores per $\mathrm{mL}$, respectively. Escapes may also occur using the Wellman root-dip method of screening. Alexander and Hoover [25] pointed out the significance that this type of assay places on escapes and recommended increasing the number of tests to compensate in order to select resistant plants for breeding purposes. Another consideration includes the bias towards dominant, major resistance genes this screening method is likely to have.

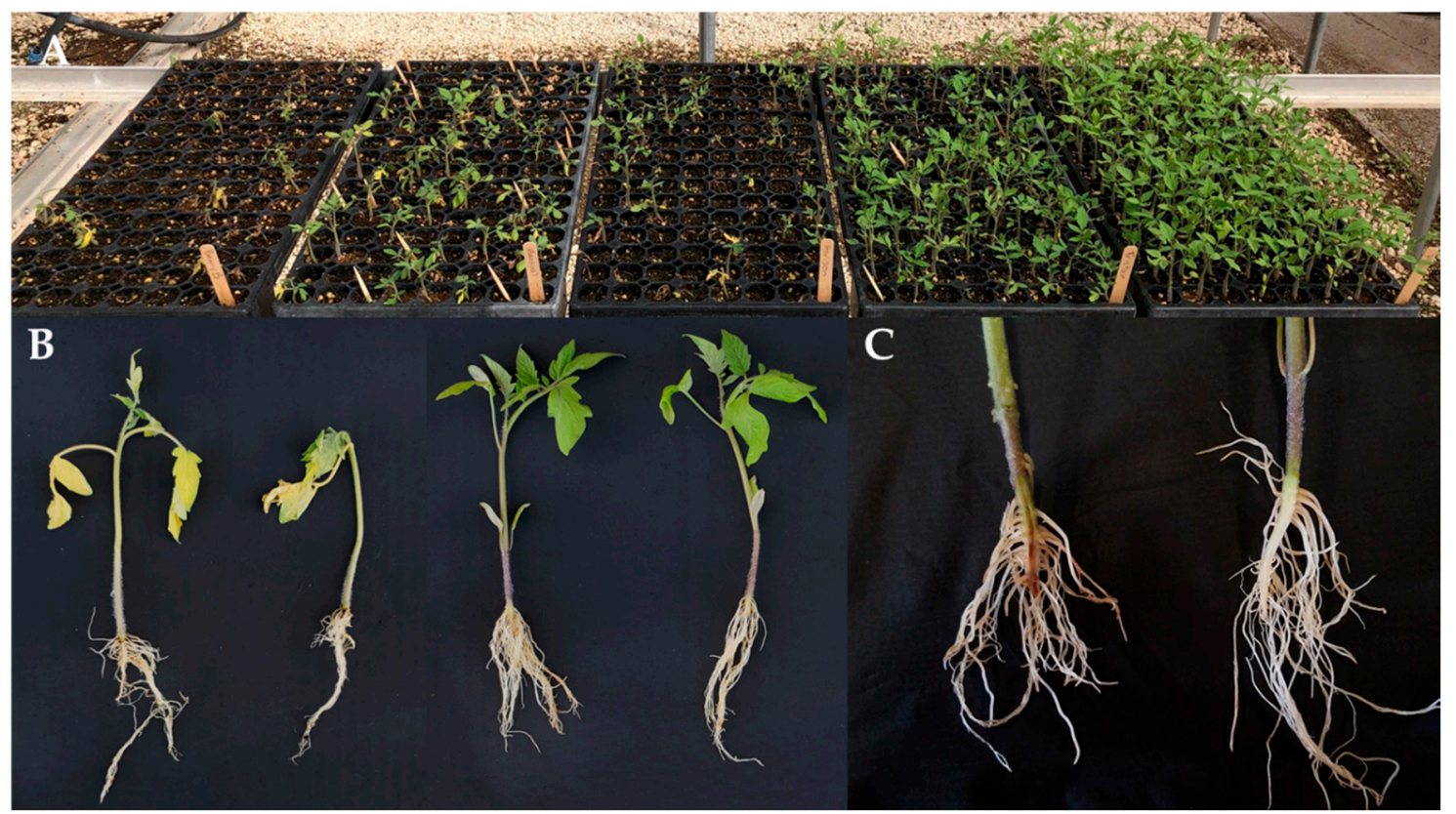

Figure 2. Symptoms observed in Fol3 seedling disease assays. (A) From left to right, trays contain 'Bonny Best' (susceptible to all three races), 'Manapal' (contains I), 'Horizon' (contains I and I-2), 'Tristar' (contains I, I-2, and I-7), and Fla. 7946 (contains I, I-2, and I-3). (B) Two susceptible plants on the left are compared with two resistant plants on the right. (C) Root dissection reveals the vascular browning in a susceptible plant (left) compared with a resistant plant (right).

Phenotypic disease screens remain a critical component of breeding for resistance to Fol, particularly in gene discovery studies. However, the limitations of seedling disease assays using the Wellman root-dip method must not be ignored. Although plants which survive the screen are likely to contain alleles which confer a level of resistance, other potentially useful resistance factors that would contribute to effective field resistance may be missed.

\section{Marker-Assisted Breeding}

The introduction of genetic markers has revolutionized plant breeding. This has been especially important in breeding for disease resistances, as breeders have often been able to reduce their dependence on costly disease assays or on natural disease pressures, and instead utilize routine marker assays to track the presence of resistance genes in their breeding populations.

The study of linkage mapping in plants opened the door to the ability to utilize genetic markers in plant breeding. Several types of molecular markers exist, and the degree to which they are used often depends on the technology required. Isozyme markers were among the first developed and utilized. Tanksley and Rick [75] developed a linkage map of isozyme markers in tomato and suggested their usefulness for introgressing genes from wild tomato species. Bournival et al. [41] identified tight linkage between the isozyme marker Got-2 and I-3, the first marker for this gene. Restriction fragment length polymorphisms (RFLPs) allowed an improved degree of specificity because of the saturation of these markers across the tomato genome. I-2 was found to be linked to RFLP marker 
TG105 [76], and Tanksley et al. [77] reported that I-3 was linked to RFLP markers TG128, TG217, and TG170.

As sequencing technologies improved and tomato genome sequences were made available, DNA sequence variations, such as simple sequence repeats (SSRs), insertion/deletions (indels), and single nucleotide polymorphisms (SNPs) were exploited for marker development. Cleaved amplified polymorphic sequence (CAPS) markers, which make use of SNPs and include restriction enzyme digestion, have been used extensively for tomato breeding applications and genetic studies, including the discovery of the $I, I-3$, and $I-7$ genes [59]. Sequence characterized amplified region (SCAR) markers can be developed using indels and cost less than CAPS markers because they do not require digestion by restriction enzymes [59]. However, indels do not occur as frequently across the genome as SNPs and may, therefore, be less useful in certain research situations such as gene mapping.

To facilitate marker assisted selection, we have compiled a list of sequence polymorphisms for $I, I-2$, and $I-3$, providing a resource for marker development in a single location (Supplementary Table S1). This is especially helpful for $I$ and $I-2$, which are absent in only a few of the genome sequences currently available to the public. For more information describing the breeding lines and methodology used, see Supplementary Methods.

Figure 3 displays polymorphisms detected in the orthologs and flanking regions of each gene, and detailed information for each polymorphism can be found in Supplementary Table S1. The lowest number of SNPs for any gene was 11, which were identified for the $I$ ortholog by comparing Fla. 7907, Fla. 7946, Fla. 8653, and Fla. 8916 to the Fol susceptible cultivar 'Yellow Pear'. Fifty-one SNPs were identified for the $I-2$ ortholog by comparing the same four Fla. breeding lines to Heinz1706. The I-3 ortholog contained the greatest number of SNPs, 148, identified by comparing Fla. 7907 and Fla. 7946 (Fol3 susceptible) with Fla. 8653 and Fla. 8916 (Fol3 resistant). These results will aid in the development of markers which are more tightly linked with, or located within, their respective genes.
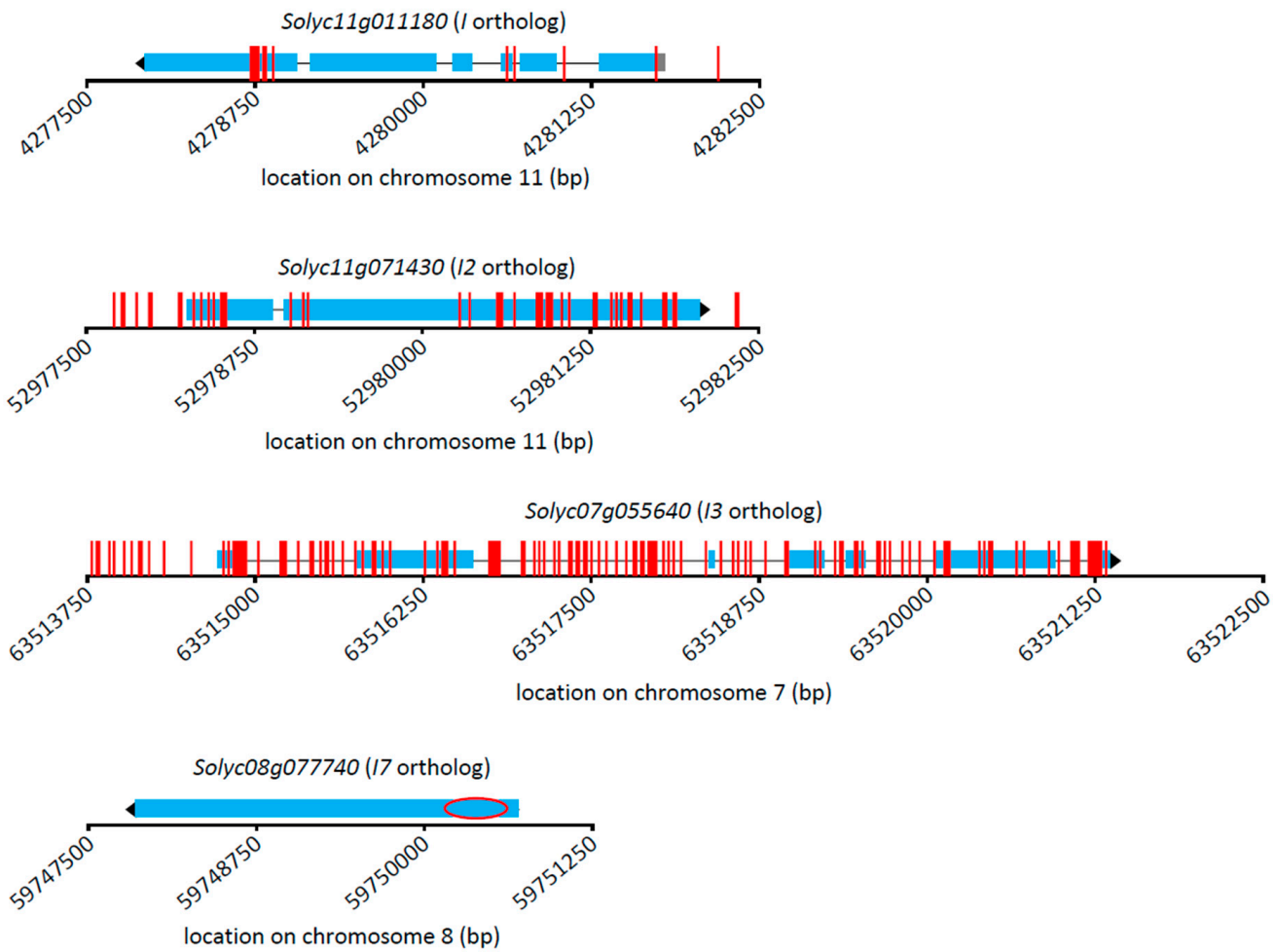

Figure 3. Single nucleotide polymorphism (SNP) sites across I gene orthologs in tomato (S. lycopersicum). Vertical red lines show locations of SNP sites. Ortholog gene models are shown at correct $x$ axis positions for Heinz 1706 (S. lycopersicum) reference (blue bar, exons; black line, introns; and gray bar, untranslated region). Ortholog gene names are given above the gene model. The red circle in Solyc08g077740 shows the location of a cleaved amplified polymorphic sequence marker previously designed for I7. A table showing SNP information for I, I-2, and I-3 can be found in Supplementary Table S1. 


\section{Durability of Resistance}

All Fol resistance genes currently used in commercial tomato cultivars are $\mathrm{R}$ genes. The durability of $\mathrm{R}$ genes is typically dependent on the ability of the pathogen to mutate in order to overcome resistance, a well-known limitation to use of $\mathrm{R}$ gene-mediated resistance in plant crops around the world [78]. It is thought that mutations in the SIX genes of Fol over time have led to the breakdown of resistance and the emergence of new races, following a zig-zag model of plant-pathogen interaction [79]. However, there is evidence suggesting that the tomato-Fol relationship is more complex than this model or the genefor-gene model implies. Fol2 was first reported just four years after the release of 'Pan America', the first cultivar with resistance to Fol [29]. It is known that Fol2 lacks Avr1, which is associated with increased aggressiveness and required for I-mediated resistance [52,54]. While it was undoubtably the selection pressure imposed via the use of the I gene which led to Fol2 becoming the dominant race impacting tomato production, it is possible that this variation among isolates existed prior to the deployment of the $I$ gene. Furthermore, the dependence of I-2-mediated resistance on two fungal effectors, the suppressive function of Avr1, and the conspicuous absence of detectable interactions between any of the $I$ genes and fungal effectors challenge the oversimplified interpretation of a gene-for-gene model in this system.

Although the efficacy of $I$ was lost relatively quickly after its deployment, the $I-2$ gene provided resistance for nearly 20 years until the emergence of Fol3, which occurred in separate locations: Australia in 1979, in Florida in 1982, and later in California in 1988 [37,38,80]. Houterman et al. [54] identified three independent point mutations in Avr2 which lead to the emergence of race 3 in isolated Fol populations, and it is likely that race 3 originated from local race 2 populations, rather than by introduction such as that on contaminated transplants [80]. Elias and Schneider [81] theorized that genetic determinants responsible for the development of new races may already exist in the pathogen population. Cultivars containing I-3 have been successfully used for the control of Fol3 over more than 30 years, but this resistance has not been as ubiquitously deployed as the $I$ or $I-2$ genes, and therefore, selection pressure for mutation in the pathogen has not been as intense. How much time remains before the pathogen overcomes $I$-3-mediated resistance?

Resistance based on quantitative trait loci (QTL) is considered a more durable and, thus, in some cases, the more preferred type of resistance compared to $\mathrm{R}$ genes [82]. Quantitative resistance is controlled by multiple genes, each contributing a small effect to the resistance phenotype, rather than resistance being conferred by a single gene. Mutation in a single Avr gene within the pathogen is unlikely to overcome such resistance, and pathogens that do overcome QTL resistance gain only a marginal advantage [78]. However, breeding for QTL-based resistance can prove challenging, especially for tomato, in which commercial cultivars are hybrids and disease resistance is often introgressed from wild tomato species. Traits introgressed from wild tomato are typically associated with linkage drag effects. Thus, developing commercial cultivars with resistance based on multiple introgressions can therefore be quite challenging, especially when effective $R$ genes are readily available. It may, however, be possible to replicate the durability of QTL-based resistance by pyramiding $\mathrm{R}$ genes, especially those representing different modes of action between the resistance genes and the effectors they recognize [83,84]. Pyramiding $R$ genes is an established approach in the development of disease resistant cultivars and stacking multiple genes for resistance to Fol3 would likely produce durably resistant tomato cultivars.

Already, $I, I-2$, and $I-3$ are commonly stacked in commercial cultivars. The $I-3$ and $I-7$ genes represent different classes of $\mathrm{R}$ genes that may have distinct modes of action [42]. I-3 and I-7 were each introgressed from S. pennellii $[39,40]$, and this species may harbor additional Fol resistance genes. The identification and introgression of novel Fol3 resistance alleles could be especially useful for pyramiding with $I-3$ and $I-7$ to promote the durability of Fol3 resistance. 


\section{Conclusions and Future Outlook}

Disease resistance remains the most effective strategy for management of Fusarium wilt, and the work to discover, utilize, and understand resistance for each of the three races as they emerged has spanned a century. In every case, resistance has been introgressed from wild tomato species in the form of major, dominant $\mathrm{R}$ genes. However, the manner in which these genes function to provide protection from Fol, and specifically how they recognize and interact with the corresponding Fol effectors, remains unknown. Although there have been efforts to explore the expression of the I genes and elucidate gene function, interpretation of the findings has not clear. Both $I-2$ and $I-3$ were detected in root, stem, and leaf tissues [50,67]; but whereas expression of $I-2$ was detected at the highest level in the xylem parenchyma cells where infection by Fol2 was also halted [67], I-3 was almost undetectable in roots [50]. Further study is necessary to shed light on the interactions between the tomato host and Fol.

Although breeding for resistance to most diseases in tomato has primarily focused on the use of $\mathrm{R}$ genes, exploring quantitative resistance may be vital to the durability of resistance. Wild species likely harbor additional Fol resistance alleles, some of which may be nonrace specific major genes or QTL-based resistances. With the genetic resources available today, mining for these resistance loci in the sequences of wild accessions and incorporating them into commercial varieties is much less cumbersome than in the past.

Although the pursuit of QTLs from wild species could prove challenging given potential for linkage-drag effects, there is opportunity to pursue QTLs affecting resistance that exist in cultivated backgrounds. 'M82', which lacks the $I-2$ gene, is reported to be partially resistant to Fol2 [47,85], and Sela-Buurlage et al. [47] reported a S. lycopersicum Fol2 resistance locus from 'M82' and located on chromosome 2. Similarly, 'Marglobe', which lacks $I$, was reported to segregate for levels of resistance to Fol1 [85]. Chitwood-Brown et al. [62] also demonstrated significantly lower Fol3 disease incidence in Fla. 8059 relative to other susceptible controls, all of which lacked I-3. While the underlying mechanisms responsible for these observations are unknown, there are many points of host-pathogen interaction which lead to either infection and colonization by the fungus or recognition and resistance by the host. Roots present many barriers to infection, including root exudates, the structure of tissues, and the timing and magnitude of response to invasive growth of a pathogen [86-88]. Finally, Gao et al. [89] reported that symptom expression was determined by the ability of a plant to restrict the colonization of the fungus in the vascular tissue. Given the variation that exists among cultivars, it is likely that at least some of these traits are heritable and may be combined to increase the effectiveness of disease resistance.

Taken together, such approaches have the potential to greatly increase the efficacy and durability of resistance, thereby contributing vital tools for tomato growers to utilize in their management of this important disease.

Supplementary Materials: The following are available online at https:/ / www.mdpi.com/article/10 .3390 /genes12111673/s1, Single nucleotide polymorphisms (SNPs) in the Solanum lycopersicum ortholog of each Fusarium wilt resistance gene were predicted from aligned whole-genome sequencing (WGS) read data to the SL4.0 version of the Heinz 1706 tomato genome assembly [90]. Illumina whole-genome raw read data sets used in this study were as follows: one i germplasm accession [Yellow Pear, Sol Genomics Network (https: / solgenomics.net), susceptible to all three races of Fol], one i-2 accession (Heinz 1706, susceptible to Fol2 and Fol3), two i-3 (Fla. 8653, Fla. 8916, susceptible to Fol3), and two I-3 (Fla. 7907, Fla. 7936, resistant to all three races of Fol). All Fla. breeding lines possess both I and I-2 and are large-fruited, fresh-market breeding lines with determinate growth habit. 'Yellow Pear' is small fruited, indeterminate, unimproved (heirloom) cultivar. Further, intracultivar SNPs in Heinz 1706 were identified in two individual Heinz 1706 plants [LA4345; seed was obtained from the Tomato Genetics Resource Center (https:/ /tgrc.ucdavis.edu)] and excluded in this study. BWA-MEM algorithm [version 0.7.17 [91]] with paired-end options was used to align the reads to the reference genome assembly [90]. After removing SNP calls supported by fewer than six reads in the WGS data, we identified SNPs in each gene. 
Author Contributions: Conceptualization, J.C.-B., S.F.H., G.E.V.; Writing-Original Draft Preparation, J.C.-B.; Writing-Review \& Editing, J.C.-B., S.F.H., G.E.V., T.G.L.; Funding Acquisition, S.F.H., G.E.V., T.G.L. All authors have read and agreed to the published version of the manuscript.

Funding: This work was supported by funding from the US Department of Agriculture award USDA-NIFA-2018-67013-27896, and by funding from the University of Florida Institute of Food and Agriculture Science Plant Breeding Graduate Initiative.

Institutional Review Board Statement: Not applicable.

Informed Consent Statement: Not applicable.

Data Availability Statement: Data is contained within the article or Supplementary Material.

Conflicts of Interest: The authors declare no conflict of interest.

\section{References}

1. Lukyanenko, A. Disease resistance in tomato. In Genetic improvement of tomato; Springer: Berlin/Heidelberg, Germany, 1991; pp. 99-119.

2. Bai, Y.L.; Lindhout, P. Domestication and breeding of tomatoes: What have we gained and what can we gain in the future? Ann. Bot. 2007, 100, 1085-1094. [CrossRef]

3. Sim, S.C.; Robbins, M.D.; Van Deynze, A.; Michel, A.P.; Francis, D.M. Population structure and genetic differentiation associated with breeding history and selection in tomato (Solanum lycopersicum L.). Heredity 2011, 106, 927-935. [CrossRef]

4. Menda, N.; Strickler, S.R.; Edwards, J.D.; Bombarely, A.; Dunham, D.M.; Martin, G.B.; Mejia, L.; Hutton, S.F.; Havey, M.J.; Maxwell, D.P.; et al. Analysis of wild-species introgressions in tomato inbreds uncovers ancestral origins. BMC Plant Biol. 2014, 14, 287. [CrossRef]

5. Gordon, T.R.; Martyn, R.D. THE EVOLUTIONARY BIOLOGY OF FUSARIUM OXYSPORUM. Annu. Rev. Phytopathol. 1997, 35 111-128. [CrossRef]

6. Sutherland, J.B.; III, A.L.P.; Crawford, D.L. Lignocellulose degradation by Fusarium species. Can. J. Bot. 1983, 61, 1194-1198. [CrossRef]

7. Michielse, C.B.; Rep, M. Pathogen profile update: Fusarium oxysporum. Mol. Plant Pathol. 2009, 10, 311-324. [CrossRef]

8. Correll, J.; Jones, J.P. Fusarium Wilt. In Compendium of Tomato Diseases and Pests, 2nd ed.; Jones, J.B., Zitter, T.A., Momol, T.M., Miller, S.A., Eds.; The American Phytopathological Society: Saint Paul, MN, USA, 2014; pp. 28-29.

9. Larkin, R.P.; Fravel, D.R. Effects of varying environmental conditions on biological control of fusarium wilt of tomato by nonpathogenic Fusarium spp. Phytopathology 2002, 92, 1160-1166. [CrossRef] [PubMed]

10. Jones, J.P.; Woltz, S.S. Cultural control of Fusarium wilt race 3 of tomato. In Proceedings of the Florida State Horticultural Society, Daytona Beach, FL, USA, 1-3 November 1983; pp. 82-83.

11. Katan, T.; Shlevin, E.; Katan, J. Sporulation of Fusarium oxysporum f. sp. lycopersici on stem surfaces of tomato plants and aerial dissemination of inoculum. Phytopathology 1997, 87, 712-719. [CrossRef] [PubMed]

12. Katan, J. Symptomless carriers of the tomato Fusarium wilt pathogen. Phytopathology 1971, 61, 1213-1217. [CrossRef]

13. Stall, R.E. Development of Fusarium wilt on resistant varieties of tomato caused by a strain different from race 1 isolates of Fusarium oxysporum f. lycopersici. Plant Dis Rep. 1961, 45, 12-15.

14. Jones, J.; Scott, J.; Woltz, S. The effect of a nine-month overseasoning period on fusarium wilt of tomato. In Proceedings of the Florida State Horticultural Society. Meeting (USA), Miami Beach, FL, USA, 3-5 November 1992.

15. De Corato, U.; Patruno, L.; Avella, N.; Salimbeni, R.; Lacolla, G.; Cucci, G.; Crecchio, C. Soil management under tomato -wheat rotation increases the suppressive response against Fusarium wilt and tomato shoot growth by changing the microbial composition and chemical parameters. Appl. Soil Ecol. 2020, 154, 18. [CrossRef]

16. Raza, W.; Ling, N.; Zhang, R.; Huang, Q.; Xu, Y.; Shen, Q. Success evaluation of the biological control of Fusarium wilts of cucumber, banana, and tomato since 2000 and future research strategies. Crit. Rev. Biotechnol. 2017, 37, 202-212. [CrossRef]

17. Basco, M.J.; Bisen, K.; Keswani, C.; Singh, H.B. Biological management of Fusarium wilt of tomato using biofortified vermicompost. Mycosphere 2017, 8, 467-483. [CrossRef]

18. Akköprü, A.; Demir, S. Biological control of Fusarium wilt in tomato caused by Fusarium oxysporum f. sp. lycopersici by AMF Glomus intraradices and some rhizobacteria. J. Phytopathol. 2005, 153, 544-550.

19. Ragsdale, N.; Wheeler, W. Methyl bromide: Risks, benefits and current status in pest control. Rev. Pestic. Toxicol. 1995, 3, 21-44.

20. Vallad, G.E.; Boyd, N.; Noling, J. A comparison of alternative fumigants to methly bromide for Florida tomato production. In Proceedings of the 2014 Annual International Research Conference on Methyl Bromide Alternatives and Emissions Reductions, Orlando, FL, USA, 11-14 November 2014; pp. 6-1-6-4.

21. Cao, X.; Guan, Z.F.; Vallad, G.E.; Wu, F. Economics of fumigation in tomato production: The impact of methyl bromide phase-out on the Florida tomato industry. Int. Food Agribus. Manag. Rev. 2019, 22, 589-600. [CrossRef] 
22. Land, C.E.; Vallad, G.E.; Desaeger, J.; van Santen, E.; Noling, J.; Lawrence, K.S. Supplemental fumigant placement improves root-knot and Fusarium wilt management for tomatoes produced on a raised bed, plasti-culture system in Florida's Myakka fine sand. Plant Dis. 2021. [CrossRef] [PubMed]

23. Jacoby, T.P. Improving the Efficacy of Methyl Bromide Alternatives for Vegetable Production in Florida. Ph.D. Thesis, University of Florida, Ann Arbor, MI, USA, 2016.

24. Bohn, G.W.; Tucker, C.M. Immunity to Fusarium wilt in the tomato. Science 1939, 89, 603-604. [CrossRef] [PubMed]

25. Alexander, L.J.; Hoover, M.M. Disease Resistance in Wild Species of Tomato: Report of the National Screening Committee. 1955. Available online: https://kb.osu.edu/bitstream/handle/1811/63048/1/OARDC_research_bulletin_n0752.pdf (accessed on 22 October 2021).

26. Scott, J.W.; Jones, J.P. Soil-borne fungal resistance in Lycopersicon pennellii accessions. In Proceedings of the Annual meeting of the American Society for Horticultural Science, Tuscon, AZ, USA, 4-8 November 1990; p. 1068.

27. Porte, W.S.; Walker, H.B. The Pan American Tomato: A New Red Variety Highly Resistant to Fusarium Wilt; US Department of Agriculture: Washington, DC, USA, 1941.

28. Paddock, E.F. A Tentative Assignment of the Fusarium-Immunity Locus to Linkage Group-5 in Tomato. Genetics 1950, 35, 683-684.

29. Alexander, L.; Tucker, C. Physiologic specialization in the tomato wilt fungus Fusarium oxysporum f. sp. lycopersici. J. Agric. Res. 1945, 70, 303-313.

30. Walter, J.M. HEREDITARY RESISTANCE TO DISEASE IN TOMATO. Annu. Rev. Phytopathol. 1967, 5, 131-160. [CrossRef]

31. Stall, R.; Walter, J. Selection and inheritance of resistance in tomato to isolates of races 1 and 2 of the Fusarium wilt organism. Phytopathology 1965, 55, 1213-1215.

32. Cirulli, M.; Alexander, L.J. A Comparison of Pathogenic Isolates of Fusarium oxysporum f Lycopersici and Different Sources of Resistance in tomato. Phytopathology 1966, 56, 1301-1304.

33. Scott, J.; Agrama, H.; Jones, J. RFLP-based analysis of recombination among resistance genes to Fusarium wilt races 1, 2, and 3 in tomato. J. Am. Soc. Hortic. Sci. 2004, 129, 394-400. [CrossRef]

34. Simons, G.; Groenendijk, J.; Wijbrandi, J.; Reijans, M.; Groenen, J.; Diergaarde, P.; Van der Lee, T.; Bleeker, M.; Onstenk, J.; de Both, M.; et al. Dissection of the Fusarium I2 gene cluster in tomato reveals six homologs and one active gene copy. Plant Cell 1998, 10, 1055-1068. [CrossRef]

35. Laterrot, $\mathrm{H}$. Localisation chromosomique de $I_{2}$ chez la tomate controlant la resistance au pathotype 2 de Fusarium oxysporum $\mathrm{F}$. lycopersici. Ann. Amelior Plantes 1976, 26, 485-491.

36. Strobel, J.W.; Hayslip, N.; Burgis, D.; Everett, P. Walter: A Determinate Tomato Resistant to Races 1 and 2 of the Fusarium Wilt Pathogen; University of Florida: Gainesville, FL, USA, 1969; p. S-202.

37. Grattidge, R.; Obrien, R.G. Occurrence of a 3rd Race of Fusarium-Wilt of Tomatoes in Queensland. Plant Dis. 1982, 66, 165-166. [CrossRef]

38. Volin, R.B.; Jones, J.P. A new race of Fusarium-wilt of tomato in florida and sources of resistance. Proc. Fla. State Hortic. Soc. 1982, 95, 268-270.

39. McGrath, D.; Gillespie, D.; Vawdrey, L. Inheritance of resistance to Fusarium oxysporum f. sp. lycopersici races 2 and 3 in Lycopersicon pennellii. Aust. J. Agric. Res. 1987, 38, 729-733.

40. Scott, J.; Jones, J. Monogenic resistance in tomato to Fusarium oxysporum f. sp. lycopersici race 3. Euphytica 1989, 40, 49-53. [CrossRef]

41. Bournival, B.L.; Scott, J.W.; Vallejos, C.E. An Isozyme Marker for Resistance to Race-3 of Fusarium-oxysporum $\mathrm{f}$ Sp Lycopersici in Tomato. Theor. Appl. Genet. 1989, 78, 489-494. [CrossRef] [PubMed]

42. Gonzalez-Cendales, Y.; Catanzariti, A.M.; Baker, B.; McGrath, D.J.; Jones, D.A. Identification of I-7 expands the repertoire of genes for resistance to Fusarium wilt in tomato to three resistance gene classes. Mol. Plant Pathol. 2016, 17, 448-463. [CrossRef] [PubMed]

43. Lim, G.; Wang, G.-P.; Hemming, M.; Basuki, S.; McGrath, D.; Carroll, B.J.; Jones, D. Mapping the I-3 gene for resistance to Fusarium wilt in tomato: Application of an I-3 marker in tomato improvement and progress towards the cloning of I-3. $J$. Australas. Plant Pathol. 2006, 35, 671-680.

44. Bournival, B.L.; Vallejos, C.E.; Scott, J.W. Genetic-Analysis of Resistances to Races 1 and 2 of Fusarium-oxysporum f Sp Lycopersici from the Wild Tomato Lycopersicon-Pennellii. Theor. Appl. Genet. 1990, 79, 641-645. [CrossRef] [PubMed]

45. Sarfatti, M.; Abu-Abied, M.; Katan, J.; Zamir, D. RFLP mapping of I1, a new locus in tomato conferring resistance against Fusarium oxysporum f. sp. lycopersici race 1. Theor. Appl. Genet. 1991, 82, 22-26. [CrossRef] [PubMed]

46. Do, T.; Catanzariti, A.-M.; Lim, G.; Jones, D. Evidence against the existence of genes for resistance to Fusarium oxysporum f. sp. lycopersici races 1 and 2 on Solanum pennellii chromosome 7 additional to I-3. In Proceedings of the V International Symposium on Tomato Diseases: Perspectives and Future Directions in Tomato Protection 1207, Malaga, Spain, 13-16 June 2016 ; pp. 19-26.

47. Sela-Buurlage, M.; Budai-Hadrian, O.; Pan, Q.; Carmel-Goren, L.; Vunsch, R.; Zamir, D.; Fluhr, R. Genome-wide dissection of Fusarium resistance in tomato reveals multiple complex loci. Mol. Genet. Genom. 2001, 265, 1104-1111.

48. Eshed, Y.; Zamir, D. An introgression line population of lycopersicon pennellii in the cultivated tomato enables the identification and fine mapping of yield-associated QTL. Genetics 1995, 141, 1147-1162. [PubMed]

49. Sato, S.; Tabata, S.; Hirakawa, H.; Asamizu, E.; Shirasawa, K.; Isobe, S.; Kaneko, T.; Nakamura, Y.; Shibata, D.; Aoki, K.; et al. The tomato genome sequence provides insights into fleshy fruit evolution. Nature 2012, 485, 635-641. [CrossRef] 
50. Catanzariti, A.M.; Lim, G.T.; Jones, D.A. The tomato I-3 gene: A novel gene for resistance to Fusarium wilt disease. New Phytol. 2015, 207, 106-118. [CrossRef]

51. Catanzariti, A.M.; Do, H.T.T.; Bru, P.; de Sain, M.; Thatcher, L.F.; Rep, M.; Jones, D.A. The tomato/gene for Fusarium wilt resistance encodes an atypical leucine-rich repeat receptor-like protein whose function is nevertheless dependent on SOBIR1 and SERK3/BAK1. Plant J. 2017, 89, 1195-1209. [CrossRef]

52. Rep, M.; van der Does, H.C.; Meijer, M.; van Wijk, R.; Houterman, P.M.; Dekker, H.L.; de Koster, C.G.; Cornelissen, B.J.C. A small, cysteine-rich protein secreted by Fusarium oxysporum during colonization of xylem vessels is required for I-3-mediated resistance in tomato. Mol. Microbiol. 2004, 53, 1373-1383. [CrossRef]

53. Houterman, P.M.; Cornelissen, B.J.; Rep, M. Suppression of plant resistance gene-based immunity by a fungal effector. J. PLoS Pathog. 2008, 4, e1000061. [CrossRef] [PubMed]

54. Houterman, P.M.; Ma, L.; van Ooijen, G.; de Vroomen, M.J.; Cornelissen, B.J.C.; Takken, F.L.W.; Rep, M. The effector protein Avr2 of the xylem-colonizing fungus Fusarium oxysporum activates the tomato resistance protein I-2 intracellularly. Plant J. 2009, 58, 970-978. [CrossRef] [PubMed]

55. Ma, L.S.; Houterman, P.M.; Gawehns, F.; Cao, L.X.; Sillo, F.; Richter, H.; Clavijo-Ortiz, M.J.; Schmidt, S.M.; Boeren, S.; Vervoort, J.; et al. The AVR2-SIX5 gene pair is required to activate I-2-mediated immunity in tomato. New Phytol. 2015, 208, 507-518. [CrossRef]

56. Ori, N.; Eshed, Y.; Paran, I.; Presting, G.; Aviv, D.; Tanksley, S.; Zamir, D.; Fluhr, R. The I2C family from the wilt disease resistance locus I2 belongs to the nucleotide binding, leucine-rich repeat superfamily of plant resistance genes. Plant Cell 1997, 9, 521-532. [CrossRef] [PubMed]

57. Schmidt, S.M.; Houterman, P.M.; Schreiver, I.; Ma, L.S.; Amyotte, S.; Chellappan, B.; Boeren, S.; Takken, F.L.W.; Rep, M. MITEs in the promoters of effector genes allow prediction of novel virulence genes in Fusarium oxysporum. BMC Genom. 2013, 14, 119. [CrossRef]

58. Cao, L.X.; Blekemolen, M.C.; Tintor, N.; Cornelissen, B.J.C.; Takken, F.L.W. The Fusarium oxysporum Avr2-Six5 Effector Pair Alters Plasmodesmatal Exclusion Selectivity to Facilitate Cell-to-Cell Movement of Avr2. Mol. Plant 2018, 11, 691-705. [CrossRef]

59. Gonzalez-Cendales, Y.; Do, H.T.; Lim, G.T.; McGrath, D.J.; Catanzariti, A.-M.; Jones, D.A. Application of CAPS markers to the mapping and marker-assisted breeding of genes for resistsance to Fusarium wilt. In Cleaved Amplified Polymorphic Sequences (CAPS) Markers in Plant Biology; Shavrukov, Y., Ed.; Nova Science Publishers, Inc.: Hauppauge, NY, USA, 2014 ; pp. 91-107.

60. Scott, J.W. Fla. 7946 tomato breeding line resistant to Fusarium oxysporum f. sp lycopersici races 1, 2, and 3. Hortscience 2004, 39, 440-441. [CrossRef]

61. Scott, J. Tomato plants heterozygous for fusarium wilt race 3 resistance develop larger fruit than homozygous resistant plants. In Proceedings of the Proceedings-Florida State Horticultural Society, Stuart, FL, USA, 31 October-2 November 1999 ; pp. 305-307.

62. Chitwood-Brown, J.; Vallad, G.E.; Lee, T.G.; Hutton, S.F. Characterization and elimination of linkage-drag associated with Fusarium wilt race 3 resistance genes. Theor. Appl. Genet. 2021. [CrossRef] [PubMed]

63. Hutton, S.F.; Scott, J.W.; Vallad, G.E. Association of the Fusarium wilt race 3 resistance gene, I-3, on chromosome 7 with increased susceptibility to bacterial spot race T4 in tomato. J. Am. Soc. Hortic. Sci. 2014, 139, 282-289. [CrossRef]

64. Li, J.; Chitwood, J.; Menda, N.; Mueller, L.; Hutton, S.F. Linkage between the I-3 gene for resistance to Fusarium wilt race 3 and increased sensitivity to bacterial spot in tomato. Theor. Appl. Genet. 2018, 131, 145-155. [PubMed]

65. Heinze, P.; Andrus, C. Apparent localization of Fusarium wilt resistance in the Pan America tomato. Am. J. Bot. 1945, 32, 62-66. [CrossRef]

66. Snyder, W.C.; Baker, K.F.; Hansen, H. Interpretation of resistance to Fusarium wilt in tomato. Science 1946, 103, 707-708. [CrossRef] [PubMed]

67. Mes, J.J.; van Doorn, A.A.; Wijbrandi, J.; Simons, G.; Cornelissen, B.J.C.; Haring, M.A. Expression of the Fusarium resistance gene I-2 colocalizes with the site of fungal containment. Plant J. 2000, 23, 183-193. [CrossRef] [PubMed]

68. van der Does, H.C.; Lievens, B.; Claes, L.; Houterman, P.M.; Cornelissen, B.J.C.; Rep, M. The presence of a virulence locus discriminates Fusarium oxysporum isolates causing tomato wilt from other isolates. Environ. Microbiol. 2008, 10, 1475-1485. [CrossRef]

69. Jelinski, N.A.; Broz, K.; Jonkers, W.; Ma, L.-J.; Kistler, H.C. Effector gene suites in some soil isolates of Fusarium oxysporum are not sufficient predictors of vascular wilt in tomato. Phytopathology 2017, 107, 842-851. [CrossRef]

70. Ma, L.J.; van der Does, H.C.; Borkovich, K.A.; Coleman, J.J.; Daboussi, M.J.; Di Pietro, A.; Dufresne, M.; Freitag, M.; Grabherr, M.; Henrissat, B.; et al. Comparative genomics reveals mobile pathogenicity chromosomes in Fusarium. Nature 2010, 464, 367-373. [CrossRef] [PubMed]

71. Li, J.M.; Fokkens, L.; Conneely, L.J.; Rep, M. Partial pathogenicity chromosomes in Fusarium oxysporum are sufficient to cause disease and can be horizontally transferred. Environ. Microbiol. 2020, 22, 4985-5004. [CrossRef]

72. Wellman, F. A technique for studying host resistance and pathogencity in tomato Fusarium wilt. Phytopathology 1939, $29,945-956$.

73. Volin, R.; Jones, J. Progress in developing resistance to Fusarium race 3 in Florida. In Proceedings of the 4th Tomato Quality Workshop, Miami, FL, USA, 7-10 March 1983; p. 105.

74. Scott, J.W.; Jones, J.P. An update on Fusarium wilt race 3 resistance. In Proceedings of the Tomato Breeders Roundtable, Sacramento, CA, USA, 6-8 March 1985; p. 13. 
75. Tanksley, S.D.; Rick, C.M. Isozymic Gene Linkage Map of the Tomato-Applications in Genetics and Breeding. Theor. Appl. Genet. 1980, 57, 161-170. [CrossRef]

76. Sarfatti, M.; Katan, J.; Fluhr, R.; Zamir, D. An RFLP marker in tomato linked to the Fusarium-oxysporum resistance gene I2. Theor. Appl. Genet. 1989, 78, 755-759. [CrossRef]

77. Tanksley, S.D.; Ganal, M.W.; Prince, J.P.; Devicente, M.C.; Bonierbale, M.W.; Broun, P.; Fulton, T.M.; Giovannoni, J.J.; Grandillo, S.; Martin, G.B.; et al. High-density molecular linkage maps of the tomato and potato genomes. Genetics 1992, 132, 1141-1160.

78. Poland, J.A.; Balint-Kurti, P.J.; Wisser, R.J.; Pratt, R.C.; Nelson, R.J. Shades of gray: The world of quantitative disease resistance. Trends Plant Sci. 2009, 14, 21-29. [CrossRef]

79. Takken, F.; Rep, M. The arms race between tomato and Fusarium oxysporum. Mol. Plant Pathol. 2010, 11, 309-314. [CrossRef] [PubMed]

80. Cai, G.; Gale, L.R.; Schneider, R.W.; Kistler, H.C.; Davis, R.M.; Elias, K.S.; Miyao, E.M. Origin of Race 3 of Fusarium oxysporum f. sp lycopersici at a Single Site in California. Phytopathology 2003, 93, 1014-1022. [CrossRef] [PubMed]

81. Elias, K.S.; Schneider, R.W. Vegetative Compatibility Groups in Fusarium-oxysporum f-sp Lycopersici. Phytopathology 1991, 81, 159-162. [CrossRef]

82. Pilet-Nayel, M.L.; Moury, B.; Caffier, V.; Montarry, J.; Kerlan, M.C.; Fournet, S.; Durel, C.E.; Delourme, R. Quantitative Resistance to Plant Pathogens in Pyramiding Strategies for Durable Crop Protection. Front. Plant Sci. 2017, 8, 1838. [CrossRef] [PubMed]

83. Douglas, E.; Halpin, C. Gene stacking. In Molecular Techniques in Crop Improvement; Springer: Berlin/Heidelberg, Germany, 2010; pp. 613-629.

84. Zhu, S.; Li, Y.; Vossen, J.H.; Visser, R.G.; Jacobsen, E. Functional stacking of three resistance genes against Phytophthora infestans in potato. Transgenic Res. 2012, 21, 89-99. [CrossRef] [PubMed]

85. Gao, H.; Beckman, C.H.; Mueller, W.C. The nature of tolerance to Fusarium oxysporum f. sp. lycopersici in polygenically field-resistant marglobe tomato plants. Physiol. Mol. Plant Pathol. 1995, 46, 401-412. [CrossRef]

86. Beckman, C.H.; Verdier, P.A.; Mueller, W.C. A System of Defense in Depth Provided by Vascular Parenchyma Cells of Tomato in Response to Vascular Infection with Fusarium-oxysporum f-sp Lycopersici, Race-1. Physiol. Mol. Plant. Pathol. 1989, 34, 227-239. [CrossRef]

87. Gordon, T.R. Fusarium oxysporum and the Fusarium Wilt Syndrome. In Annual Review of Phytopathology; Leach, J.E., Lindow, S.E., Eds.; Annual Reviews: Palo Alto, CA, USA, 2017; Volume 55, pp. 23-39.

88. Baetz, U.; Martinoia, E. Root exudates: The hidden part of plant defense. Trends Plant Sci. 2014, 19, 90-98. [CrossRef] [PubMed]

89. Gao, H.; Beckman, C.H.; Mueller, W.C. The rate of vascular colonization as a measure of the genotypic interaction between various cultivars of tomato and various formae or races of Fusarium oxysporum. Physiol. Mol. Plant Pathol. 1995, 46, 29-43. [CrossRef]

90. Fernandez-Pozo, N.; Menda, N.; Edwards, J.D.; Saha, S.; Tecle, I.Y.; Strickler, S.R.; Bombarely, A.; Fisher-York, T.; Pujar, A.; Foerster, H.; et al. The Sol Genomics Network (SGN)-from genotype to phenotype to breeding. Nucleic Acids Res. 2015, 43, D1036-D1041. [CrossRef] [PubMed]

91. Li, H.; Durbin, R. Fast and accurate long-read alignment with Burrows-Wheeler transform. Bioinformatics 2010, 26, 589-595. [CrossRef] [PubMed] 